\title{
A Review of Research on Virtual Simulation in Education and Teaching
}

\author{
Xiang Ming \\ Chengdu Polytechnic \\ Tourism school \\ Chengdu Polytechnic \\ Chengdu, CHINA \\ xiangming2008@gmail.com
}

\begin{abstract}
At present, virtual simulation technology has been widely used in various industries, more attention has been paid especially in the commercial area. However, it is relatively slow in education. For more systematic and comprehensive understanding of the research status of virtual simulation in teaching, 113 journal articles, 128 master theses and doctoral theses has been collected. Through the classification and analysis of the literature, the teaching research based on virtual simulation is mainly focused on: theoretical research on the combination of virtual simulation and education, application of virtual simulation in majors and courses, key factors affecting the application of virtual simulation in tourism teaching. Based on the summary, it is believed that the combination of virtual simulation technology and teaching is still on the initial stage, and the application of virtual simulation technology in education especially vocational education will be a hot topic.
\end{abstract}

Keywords_-Virtual Simulation, Teaching, Review, Education

\section{INTRODUCTION}

Virtual Simulation, also known as Virtual Reality (VR), is a kind of virtual world which is created by the high-speed computer system and can obtain the interactive experience with the environment. Through the visual, auditory, tactile and other effects on the user, Virtual Simulation can make dynamic interaction response on the user's control behavior, which allows users to get into the role of experience in the synthetic environment [1].

Virtual Reality is developing rapidly, and it has been widely used. The application of virtual reality in education mainly includes science and technology research, virtual campus, virtual teaching, virtual training, virtual experiment and so on. Virtual teaching is a good embodiment of the application of virtual reality in education, which complete the teaching demonstration, explore and other aspects, provide an experiential teaching environment for students, has gradually become a new form of education and teaching.

For more systematic and comprehensive understanding of the research status of virtual simulation in teaching, the author took the "virtual simulation" and "teaching" as the theme, from 2003 to 2015 years, collected 113 journal articles, 128 master theses and doctoral theses in EBSCOHost (http://search. Ebscohost.com), Science Direct (http://www. Sciencedirect. com/) and CNKI (http://www.cnki.net). Through the classification and analysis of the literature, the teaching research based on virtual simulation is mainly focused on: theoretical research on the combination of virtual simulation and education, application of virtual simulation in majors and courses, key factors affecting the application of virtual simulation in tourism teaching. Theoretical research on the combination of virtual simulation and education

\section{A. Learning Theories}

The application of virtual reality in education is based on a certain educational theory, especially the learning theory, which is in the core position. The greatest impact on the learning theory of virtual reality includes Behavioral Theory, Cognitive Theory, Constructivism and Humanistic Learning Theory.

- Behavioral Theory advocated "presenting content (stimulus), receive information, to respond, Strengthening timely (evaluation)" in teaching [2]. From the perspective of behaviorism, virtual simulation in education has the following effects: First, it can observe the change of students' behavior understanding. Second, it enhances students' learning motivation. Third, it strengthens the exercise of operational knowledge..

- Cognitive Theory emphasizes that teachers should be able to create good and suitable learning environment and learning conditions for students in order to stimulate students' intrinsic motivation and promote their effective learning. The application of virtual simulation in education can extend the user's cognitive senses, thereby increasing the width and depth of knowledge of learners. At the same time, it can help users to overcome the limitations of subjective awareness with the computer.

- Constructivism emphasized, in the process of selection and development of teaching strategies, the key step is to construct the teaching situation, and it promotes the double subject teaching philosophy of "teacher leading and student subject", teachers should be able to become facilitators, helpers, students become into the main body of learning information processing.

- Humanistic Learning Theory thought, cultivate students' initiative spirit in teaching, fully mobilize their rich 
emotional factors, and finally establish a harmonious relationship between teacher-student and studentstudent. Virtual simulation can enhance students' participation in learning activities by creating the threedimensional environment, students participate in teaching activities in the process of learning knowledge, which can improve students' learning autonomy.

\section{B. Teaching theory based on virtual simulation}

- Anchored instruction, also known as "case-based teaching" or "problem-based teaching". After the real problem is setting, the content and process of teaching should be established, students' learning needs to be gradually excited when they are exposed to the actual situation. And then, communicate and cooperate with other students, feel the complete process from identify and propose objectives to achieving the goals with independent inquiry-based learning [3].

- Edgar Dale, an American educator, proposed "cone of experience", the theory divides a variety of experience into three categories and ten levels in accordance with their level of abstraction, forming a pyramid structure. The actual significance of this theory is that it is easier to acquire knowledge and skills from the direct to the indirect, from the concrete to the abstract. It also plays a great role in the development of the experimental teaching system [4].

- Social presence refers to the degree of person communicate with others is seen as "real people" and the degree of induction to communicate with others in the social media environment [5]. In the virtual learning environment, social presence is one of the best concepts of describing how people conduct social interaction [6]. Give play to the role of social presence in online learning so that learners learn self-confidence, happiness. It is of great significance to apply social presence as influence factor into instructional design, platform design, and resource design [7].

\section{APPLICATION OF VIRTUAL SIMULATION IN MAJORS AND COURSES}

\section{A. Application of virtual simulation in majors}

Research mostly focus on the relationship between the virtual simulation and the major, exploring the application prospecting in the field of major.

Guo Yang analyzed the application, prospect and function of virtual reality in landscape design, and proposed the general trend of constructing virtual training room [8]. Liu Xiaoyu analyzed the advantages and disadvantages of applying virtual reality technology to tour guides, and put forward the correct use of virtual reality technology, and timely update technology [9].

\section{B. Application of virtual simulation in courses}

Research mainly concentrate on the curriculum design theory, curriculum development and teaching mode.
Curriculum design is to arrange all aspects of curriculum teaching, so that teaching can be carried out smoothly. Posner and Rudnitsky pointed out that the course of any systematic approach is to be carried out within the scope of one theoretical framework [10].Most of the curriculum design is based on the three major centers around the subject, the learner and the problem. In the course of research, it is usually used in the field of curriculum to determine the application of one or several design methods.

The teaching practice mode based on virtual reality mainly includes: task-oriented, problem inquiry, interactive scene, incentive and feedback mechanism and so on. In the specific research of many scholars, it is often based on their own curriculum characteristics, designed a variety of targeted teaching mode. Based on the analysis of teaching theory, Yin Jun designed the experimental teaching model of " taskoriented + problem inquiry + interactive scene + incentive and feedback mechanism ", that integrate the teaching contents and the scene design of virtual reality, causes the presentation of teaching contents appears diversified, deepen students' perceptual knowledge of Economics and Management, and advocate students' autonomous learning, promote students interaction, can effectively improve the quality of experimental teaching [11].

\section{RESEARCH ON THE KEY FACTORS INFLUENCING THE APPLICATION OF VIRTUAL SIMULATION TECHNOLOGY IN TOURISM TEACHING}

\section{A. Attitude towards virtual technology in Teaching}

Ageel (2012) thinks that teachers' positive attitude plays a decisive role in the successful application of information and communication technology in teaching [12]. Because the teacher's attitude towards the new technology will not only affect their own use of the experience of information technology, but also the impact on the students he taught [13].

Many scholars' research results show that, teachers and students are positive attitude for the application of digital information technology in learning and teaching.

For example, Eraqi (2011) proposed students and teachers hold a positive attitude on application of digital system in tourism education in the hypothesis, a questionnaire survey was conducted on 2 universities in Egypt Tourism Specialty of 1296 teachers and students, support the hypothesis. The academic staff in the two faculties had a very good positive attitude toward e-learning as they see the Internet as a valuable resource for developing their course materials. Sundara L (2013) performed a group test on 58 students, the results show that students have a positive attitude towards experimental study based on virtual laboratory.

What factors will affect the attitude of teachers and students in the teaching of virtual simulation technology in tourism?

1) Proficiency in the use of virtual simulation technology.

For example, Eraqi and other scholars' study shows that students and teachers have the corresponding basic skills before the use of digital teaching projects. The more skilled in 3D simulation operation, the more "Flow Experience" can be 
obtained, this "Flow Experience" will positively affect students' attitude towards digital learning [14].

2) The reasonable design of learning content and timely update.

How to improve the students and teachers' interest in using virtual simulation technology?

- A comprehensive understanding of virtual simulation technology. In order to fully and scientifically understand the digital virtual technology, teachers in the classroom can show some cases of the application of digital virtual technology in tourism and hotel industry. Then the students have a comprehensive and scientific understanding of the digital virtual technology and its advantages. And the next step is to let the students have a strong interest in the technology [15].

- Skilled use of digital virtual simulation technology. This kind of technology is rich in content, in addition to 3D simulation technology, but also computer operation, Internet use and the social media based on Web2.0, etc. Teachers should consciously cultivate the habit of using these techniques, and encourage students to use digital virtual simulation technology in life and learning.

- Timely and effective feedback.

\section{B. Integration of the digital virtual technology and the actual teaching conditions}

Digital virtual technology cannot fully meet the teaching, in the teaching process, the technology is important; the formation of a new teaching mode using the existing technology is the core of the work [16]. How to effectively integrate the digital virtual technology and the actual teaching conditions is a difficult problem for teachers. This integration is not a simple superposition, but to choose the variety of learning tools, learning resources, learning strategies, and carefully designed into the teaching process [17].

Wang Jingang (2011) [18]has carried on the virtual simulation practice teaching in higher vocational education, $\mathrm{He}$ stressed that the virtual reality technology need to deal with the relationship between "virtual practice and practical training, skills training and emotional education, information technology and professional skills" in teaching practice, and puts forward 5 steps of virtual simulation practice teaching design, "teaching goal analysis, learning task design, construction of virtual simulation training teaching platform, teaching process design, teaching implementation and evaluation", construct the cooperative inquiry learning mode based on the typical project.

The combination of the digital virtual technology and the actual teaching conditions requires teachers to design effective teaching mode, which is more specific requirements for teachers' curriculum design ability and the mastery of virtual simulation teaching resources. The author thinks that the teaching design is suitable to adopt "mixed teaching method". This is widely used in digital teaching, distance education and the research of virtual teaching, because it can combine the advantages of traditional learning methods and digital learning or network learning [19], reflecting the mixture of the teaching mode based on different teaching theories, teachers' leading and students' participation, the different learning environments, the different teaching media, classroom teaching and virtual classroom [20].

Mou Zhansheng (2014) [21] designed the model of blended learning. First, fore-analysis contains analysis of learners, learning content and learning resources. Then, learning activity design, divided into small units of knowledge according to the previous analysis, and then, analysis the specific teaching objectives and knowledge types of each units in order to determine the specific teaching forms, and the preparation of relevant information. This is the core content of hybrid learning model. Finally, evaluation design, using diversified evaluation methods, emphasizes the combination of formative evaluation and final evaluation. It is required to constantly sum up experience and improve the hybrid learning model according to the status of the students 'mastering degree.

\section{System design and technical support}

The technology realization of virtual simulation system is mainly focused on the aspects of engineering technology, medical anatomy and so on. In tourism teaching, Yang Gengsheng (2010) [22] thought that we should adopt the simple virtual reality system in the tourism teaching based on the consideration of the price and the difficulty of realization. He compared the advantages and disadvantages of several virtual reality systems in tourism teaching, such as 3D model simulation, Video Virtual, 3D panoramic virtual, 3D Digital Simulative.

The construction of tourism virtual simulation system needs a large amount of funds to be invested in the early stages. In order to make full use of this platform to achieve efficient operation requires that the construction platform is not restricted to limited professional courses. In the long term, we should think about the knowledge update and functional development, and improve the ability of independent research and development, to meet the needs of multi-discipline teaching design, to achieve good social and economic benefits [23].

When using virtual simulation technology, not only strengthening the construction of computer network hardware resources through the expansion of experimental facilities and equipment, laying computer network, but also strengthen the construction of software resources through design teaching courseware scientifically, develop repositories systematically, compile experiment and training teaching materials comprehensively, and build the teaching staff appropriately.

\section{CONCLUSION}

From the existing content of these studies, it is believed that the combination of virtual simulation technology and teaching is still in the initial stage, researchers in the field of education have been aware of the advantages and effects of virtual simulation technology to teaching. However, because of the expensive equipment, it is less used in practical teaching. So, there is more research in the macro level, small number of practical research has only made some tentative ideas, which is rarely verified by practical teaching. Therefore, the research 
and application of virtual simulation technology in the field of education will be a hot topic in the present and the near future. Virtual simulation technology has been referred to an important position especially in vocational education.

\section{REFERENCES}

[1] Huang Xinyuan. Virtual reality technology and application [M]. Beijing: Science press, 1999(5) .127-129(In Chinese)

[2] Hu Weixing,Li Meifeng. The development of information technology classroom teaching strategies in elementary and middle schools [M]. Beijing: Chinese audio-visual education, 2001(7).(323) (In Chinese)

[3] Liu Yanju. The role of anchored teaching mode and the diversification of Teachers -- the application of Constructivism Theory in the teaching of College English listening and speaking [J]. Journal of Xi'an International Studies University.2009(2) .110-113. (In Chinese)

[4] Xiao Hongting. "The tower of experience" theory and Its Enlightenment on Chinese teaching of [J]. Read and write (periodical), 2009(7) .73-82. (In Chinese)

[5] Teng Yan Yang, a summary of the study of social presence in the field of [J]. modern educational technology .2013(3) .64-70. (In Chinese)

[6] Li Xiaofeng. Study on the influencing factors of social being in virtual learning community [D]. Jilin: Jilin University,2011. (In Chinese)

[7] Qu Yi. The analysis of the elements of the teaching mode and the exploration of [J]. Education Exploration, 2005(5)39-40. (In Chinese)

[8] Guo Yang, Zhang Lei. Research on the teaching and practice of virtual reality technology in landscape architecture [J]. Shanxi architecture.2014(7) .263-264. (In Chinese)

[9] Liu Xiaoyu. The application of virtual reality technology in the teaching of tour guides in Higher Vocational Colleges [J]. Journal of Career Academy, Jiamusi.2015(3).19-20. (In Chinese)

[10] George J Posner, Alan N. Rudnitsky. Course Design[M].( 2nd ed) . New York: Longman, 1990.

[11] Yin Jun. Virtual experiment teaching mode of higher education. Based on thecloud[J] . Journal of Higher Education.2015(22).76-77(In Chinese)

[12] Mohammed Ageel.The Role of Virtual Learning Environment in Improving Information and Communcation Tecnology Adoption in Teaching Exploring How Virtual Learning Environments Improve.2nd
International Conference on E-Learning \& Knowledge Management Technologies ( ICEKMT 2012 ). University Teacher's Attitudes about the Use of Information and Comuncation Technology

[13] Y. Gulbahar, and I. Guven, "A Survey on ICT Usage and the Perceptions of Social Studies Teachers in Turkey" Educational Technology \& Society, $11(3), 37-51.2008$

[14] Yu-Chih Huang, Sheila. Backman \& Kenneth F. Backman."Student Attitude Toward Virtual Learning in Second Life: A Flow Theory Approach"Journal of Teaching in Travel \& Tourism.2010(10)312-334, DOI: $10.1080 / 15313220.2010 .525425$

[15] Huang Yi, based on the digital virtual technology to explore the landscape design teaching [J]. education exploration.2013.39-41(In Chinese)

[16] Wang Yan, Zheng Lanqin, practice, reflection and exchange: focusing on the international mixed teaching research -- a summary of the Third International Conference on [J]. Modern Distance Education Research,2010,(5) .7-11. (In Chinese)

[17] Li Xiaoli, Li Lei, Xu Lianrong, mu Zhijia. Teaching design and Application Research on the effectiveness of virtual learning environment Chinese audio-visual education support.2014 (2) P119144. (In Chinese)

[18] Wang Jingang. Research on the application of virtual reality technology in the practical teaching of higher vocational education [J]. China Vocational and technical education,2011,23.76-80. (In Chinese)

[19] He Kekang,New development of theory of educational technology from Blending Learning[J] E-education research,2004, (3) (In Chinese)

[20] Li Kedong, Zhao Jianhua. Study on the principle and application mode of blended learning [J]. audio-visual education,2004 (7) .1-6. (In Chinese)

[21] Mou Zhansheng, Dong Bojie. Research on hybrid learning model based on a case study of Coursera platform MOOC [J], Modern educational technology.2014 (5) (In Chinese)

[22] Yang Gengsheng. The application of Virtual reality technology in tourism teaching $[\mathrm{J}]$. Journal of Xinjiang Education Institute.2010(6).111-114(In Chinese)

[23] Yang Xingyue. The application and thinking of Virtual simulation experiment in the practice teaching of Tourism Management [J]. market weekly.2015(12) (In Chinese) 